\title{
Responses of grape berry anthocyanin and titratable acidity to the projected climate change across the Western Australian wine regions
}

\author{
Nyamdorj N. Barnuud • Ayalsew Zerihun • \\ Freddie Mpelasoka • Mark Gibberd • Bryson Bates
}

Received: 11 March 2013 / Revised: 31 July 2013 / Accepted: 19 August 2013 /Published online: 13 September 2013

(C) The Author(s) 2013. This article is published with open access at Springerlink.com

\begin{abstract}
More than a century of observations has established that climate influences grape berry composition. Accordingly, the projected global climate change is expected to impact on grape berry composition although the magnitude and direction of impact at regional and subregional scales are not fully known. The aim of this study was to assess potential impacts of climate change on levels of berry anthocyanin and titratable acidity (TA) of the major grapevine varieties grown across all of the Western Australian (WA) wine regions. Grape berry anthocyanin and TA responses across all WA wine regions were projected for 2030, 2050 and 2070 by utilising empirical models that link these berry attributes and climate data downscaled (to $\sim 5 \mathrm{~km}$ resolution) from the csiro_mk3 5 and miroc3_2_medres global climate model outputs under IPCC SRES A2 emissions scenario. Due to the dependence of berry composition on maturity, climate impacts on anthocyanin and TA levels were assessed at a common maturity of $22{ }^{\circ}$ Brix total soluble solids (TSS), which necessitated the determination of when this maturity will be reached for each variety, region and warming scenario, and future period. The results indicate that both anthocyanin and TA levels will be affected negatively by a warming climate, but the magnitude of the
\end{abstract}

Electronic supplementary material The online version of this article (doi:10.1007/s00484-013-0724-1) contains supplementary material, which is available to authorized users.

N. N. Barnuud $\cdot$ A. Zerihun $(\triangle) \cdot$ M. Gibberd

Department of Environment and Agriculture, Curtin University,

Margaret River Education Campus, Margaret River, WA 6285,

Australia

e-mail: a.zerihun@curtin.edu.au

F. Mpelasoka

Land and Water, CSIRO, Acton, ACT 2601, Australia

B. Bates

Marine and Atmospheric Research, CSIRO, Floreat, WA 6014,

Australia impacts will differ between varieties and wine regions. Compared to 1990 levels, median anthocyanins concentrations are projected to decrease, depending on global climate model, by up to $3-12 \%$ and $9-33 \%$ for the northern wine regions by 2030 and 2070 , respectively while $2-18 \%$ reductions are projected in the southern wine regions for the same time periods. Patterns of reductions in the median Shiraz berry anthocyanin concentrations are similar to that of Cabernet Sauvignon; however, the magnitude is lower (up to $9-18 \%$ in southern and northern wine regions respectively by 2070). Similarly, uneven declines in TA levels are projected across the study regions. The largest reductions in median TA are likely to occur in the present day warmer wine regions, up to $40 \%$ for Chardonnay followed by $15 \%$ and $12 \%$ for Shiraz and Cabernet Sauvignon, respectively, by 2070 under the high warming projection (csiro_mk3_5). It is concluded that, under existing management practices, some of the key grape attributes that are integral to premium wine production will be affected negatively by a warming climate, but the magnitudes of the impacts vary across the established wine regions, varieties, the magnitude of warming and future periods considered.

Keywords Anthocyanin - Cabernet Sauvignon . Chardonnay $\cdot$ Climate change $\cdot$ Climate impact $\cdot$ Maturity dates $\cdot$ Shiraz $\cdot$ Titratable acidity $\cdot$ Vitis vinifera $\cdot$ Western Australia Wine Regions

\section{Introduction}

Despite our continually advancing knowledge in management practices to manipulate grapevine growth and development, viticulture remains a sector highly vulnerable to climate change due to the narrow climate niche for producing premium quality grapes and wines (Jones 2006). Past research 
relating to climate change impacts on viticulture projected significant impacts on multiple aspects including phenology (Jones and Davis 2000a; Hayhoe et al. 2004; Webb et al. 2007; Hall and Jones 2009; Caffarra and Eccel 2011), yield (Bindi et al. 1996; Lobell et al. 2006), grape and wine quality (Jones et al. 2005; Webb et al. 2008) and disease pressure (Chakraborty et al. 1998; Salinari et al. 2007).

Studies that examined climate change impacts on phenology generally project advancements in grapevine phenology with a consequence that the critical berry-ripening phase falls in the warmer part of the growing season (e.g. Hayhoe et al. 2004; Webb et al. 2007; Hall and Jones 2009; Sadras and Petrie 2011; Webb et al. 2011). Given that high temperature during the ripening period typically has negative impacts on several key berry quality attributes (e.g. Barnuud et al. 2013; Nicholas and Durham 2012; Mori et al. 2007), the phenology shift is likely to compound the effect of the projected rise in the growing season temperature (Webb et al. 2007). Similarly, Hayhoe et al. (2004) predicted an earlier ripening period by up to 2 months by the end of this century, and suggested that an earlier grape maturity might lead to reduced grape quality in California.

In many of the currently established wine regions, future climate change is also likely to reduce proportions of the current areas that are suitable for premium wine production. White et al. (2006) suggested that the premium wine grape growing regions of the United States would decline by more than half by the end of this century due to increases in extreme hot days. In Australia, Hall and Jones (2009) indicated that, by 2070 , about $30 \%$ of the current wine regions are likely to experience a growing season temperature warmer than what is considered suitable for premium wine production. More recently, Hannah et al. (2013) have projected that, by 2050, $22 \%$ and $73 \%$ of the viticultural areas, respectively, in the non-Mediterranean and Mediterranean climate regions of Australia are likely to be unsuitable for premium winegrape production if a high greenhouse gas emissions pathway called the representative concentration pathway 8.5 , is realised. It also needs to be recognised, however, that impacts of climate change on wine quality across the wine regions of the world are likely to vary both in size and even direction of effect depending on a region's current climate and the magnitude of future warming (Jones et al. 2005).

The findings of the studies cited above indicate the possible direction of climate change impacts on grape and wine quality. However, grape and wine quality is a subjective concept; no single measurable parameter defines overall quality objectively. Consequently, studies to date have utilized vintage or wine ratings as proxy measures of grape or wine quality. For example, several researchers (Jones and Davis 2000b; Nemani et al. 2001; Jones et al. 2005; Storchmann 2005; Sadras et al. 2007) used vintage ratings (in one or another format) as a wine quality indicator and linked it to climate variables. Webb et al. (2008) identified grape price as an alternative grape quality measure in Australian conditions and used it for climate change impact assessment. Similarly, historical wine prices and climate variable relationships were investigated to predict wine quality in Bordeaux (Ashenfelter 2008).

Grape berry colour and acidity are considered as some of the key parameters of grape quality (Francis and Newton 2005) and levels of these attributes play important role for final wine quality. However, potential impacts of climate change on these grape quality attributes have not been evaluated quantitatively. Thus, the objectives of this study were to evaluate potential impacts of future climate change on grape berry anthocyanin concentrations and titratable acidity (TA) of the major wine grape varieties (Cabernet Sauvignon, Shiraz and Chardonnay) across all the Western Australian (WA) wine growing regions. This study differs from earlier climate change impact studies for viticulture in that it employs variety-specific (parameterized) empirical models, which were developed from measured grape quality and climate data covering the study regions (Barnuud et al. 2013). Grape berry anthocyanin and TA surfaces were constructed using highresolution $(\sim 5 \mathrm{~km})$ global climate model (GCM) outputs. The fine resolution GCM outputs made it possible to examine inter-, and intra-regional differences of grape quality attribute changes under future climate.

\section{Materials and methods}

\section{Study regions}

The study covered all of the Western Australian (WA) wine regions. Currently, these are divided into nine geographic indications (GIs) (Fig. 1). Regions so delineated are thought have sufficiently different environmental characteristics that give rise to wines with distinct characters attributable to a geographic region (http://www.ipaustralia.gov.au ). To enable extraction and derivation of climate index and berry composition statistics for individual regions, a series of polygon features of the WA GIs were created by accurately digitising the official WA wine region maps in ArcGIS 9.3 (ESRI, Redlands, CA).

\section{Historical climate data}

High spatial resolution daily minimum and maximum temperatures and rainfall data on a $0.05^{\circ} \times 0.05^{\circ}$ latitude/ longitude grid for a baseline period (1975-2005) were obtained from the Australian Water Availability Project, AWAP data set (Jones et al. 2007). These are spatially interpolated from the Bureau of Meteorology weather stations network data (Jones et al. 2007). 
Fig. 1 Geographic indications (GI) of Western Australian wine regions. Statistics of climate variables and berry chemistry surfaces were calculated from grid points (dots) within a GI boundary line as illustrated in inset. Grid resolution is $0.05^{\circ} \times 0.05^{\circ}(\sim 5 \mathrm{~km})$. The West Australian GI lie within $31^{\circ} \mathrm{S}-35^{\circ} \mathrm{S}$ and $115^{\circ} \mathrm{E}-119^{\circ} \mathrm{E}$

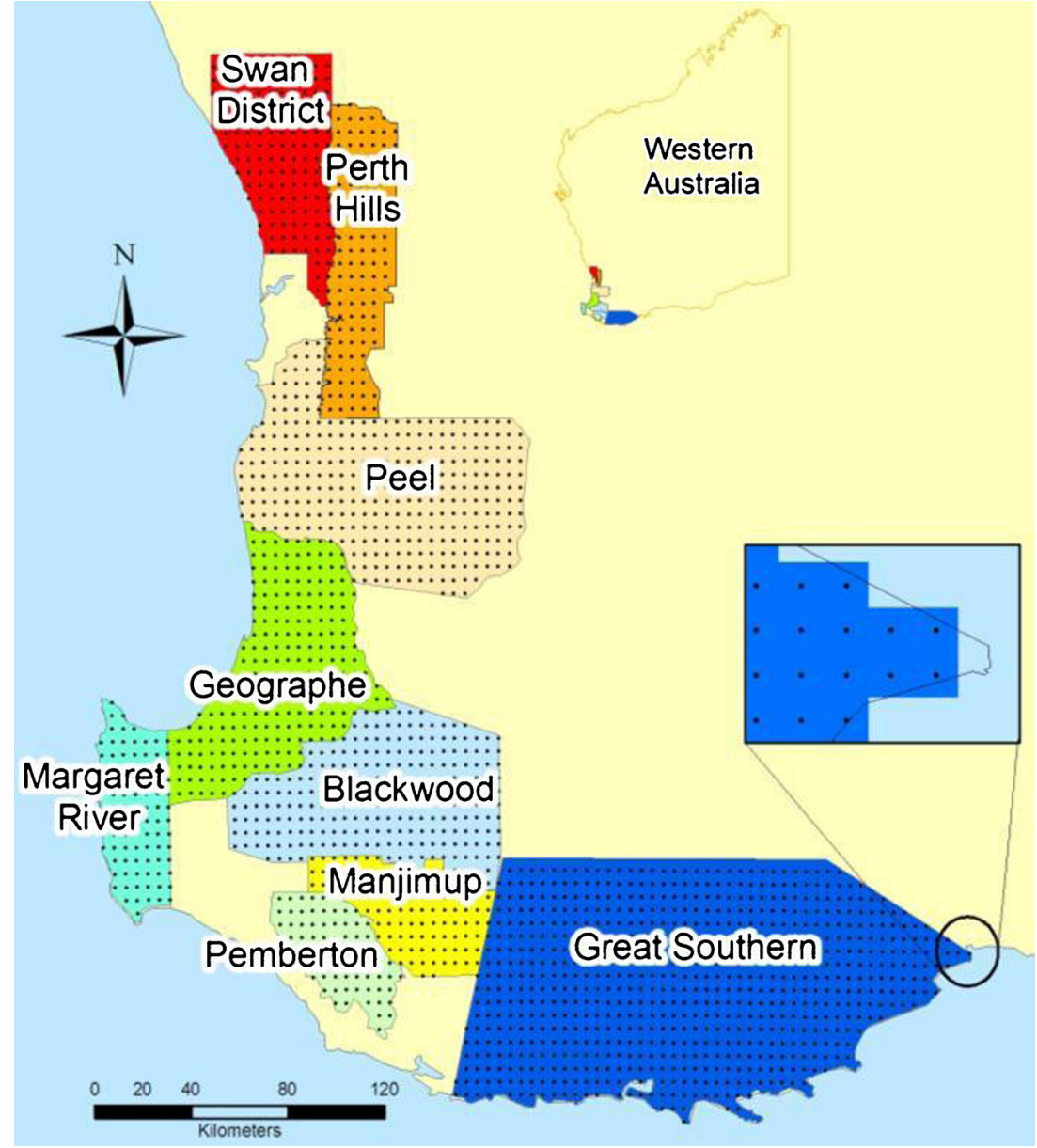

Construction of projections for future (2030, 2050 and 2070) climate sequences

Regional projections of future climate sequences were constructed in three steps as follows: firstly, three sets of climate change projections associated with low, medium and high range global warming estimates under the IPCC SRES A2, which is a relatively high emissions scenario, (IPCC 2007) were obtained from the archive of the phase three coupled model inter-comparison project (CMIP3) for ten GCMs (Supplementary Table S1) for the periods 2030, 2050 and 2070. These GCMs were selected based on their ranked performance in reproducing historical climate (temperature and rainfall) for the study regions, i.e. the south west of Western Australia (Perkins et al. 2007; CSIRO and Bureau of Meteorology 2007). Secondly, an empirically determined pattern-scaling approach (Mitchell 2003; Hennessy et al. 1998) was used for estimating responses of local climate variables to global warming. Briefly, for the climate variables of interest, their patterns of change were estimated from slopes of the linear regressions of the seasonal mean of each local climate variable, for each GCM grid-cell, on global average temperatures (Hennessy et al. 1998). The projections for each future period $(2030,2050$ and 2070) were produced from scaling local patterns of change (per degree of global warming) from each GCM by IPCC estimates of global warming for the three periods relative to baseline period. Thirdly, the scaled projections were applied subsequently to the observed historical daily time series (1975-2005) on a $0.05 \times 0.05^{\circ}$ grid to generate plausible future climate sequences for each grid-cell. The scaling approach applied here has been commonly used for climate impact assessment studies (e.g. Zhang 2005; Mpelasoka and Chiew 2009) and is considered a useful tool for downscaling coarse scale GCM outputs into fine scale climate projections (Mitchell 2003; Whetton et al. 2005).

The ten GCMs, together with the three warming estimates (low, medium and high), resulted in 30 different possible climate projections for each of the three future periods. For this study, after determining the median temperature projections for the grapevine-growing season across each of the nine wine GIs, the number of models was reduced from ten to two. The two selected GCMs represented the highest (csiro_mk3_5) and lowest (miroc3 2 medres) warming in the median growing season temperature (GST) across the WA wine regions, and hence captured the broadest projection ranges among the GCMs evaluated here (Supplementary Table S1). 
Projection of grape maturity dates

Concentrations of berry anthocyanin and TA vary with the degree of berry maturity (Esteban et al. 2002), which is typically defined in terms of ${ }^{\circ}$ Brix total soluble solids (TSS). This raised two aspects that should be considered. Firstly, in order to assess climate impacts on these berry traits across varieties, wine regions and projection periods, it was pertinent to use a common maturity level. Here, a common maturity of $22^{\circ}$ Brix TSS was used (Barnuud et al. 2013). Secondly, it was necessary to estimate the dates when the $22{ }^{\circ}$ Brix will be reached for each variety, grid-cell and projection period. This is because the anthocyanin and TA models contain timeintegrated climate indices (Barnuud et al. 2013). These indices are integrals over the growing season (here defined as the period between 1 October and the date when each variety's berry attained $22{ }^{\circ}$ Brix) or parts thereof, such as the ripening period (the 30 days period preceding the maturity). In this work, maturity dates were estimated from empirically determined relations between observed dates of maturity and climate (Barnuud 2012). This approach offers several candidate models; the final models selected, however, were those that had commonality in terms of predictor climate variables. The maturity date models provided estimates of the growing season lengths as well as timing of ripening periods. Climate variables for the growing seasons (or ripening periods) that were specific to each variety were then recalculated from the modelled maturity dates to estimate responses of berry anthocyanin and TA to the projected climate.

\section{Construction of berry anthocyanin and TA surfaces}

Construction and spatial analyses of berry anthocyanin and TA surfaces for current and future climates were carried as follows: firstly, the WA GIs feature maps were created in ArcGIS (ESRI, Redlands, CA) by digitising the hard copy maps, which were in accordance with the descriptions of GIs of the Australian wine regions. Secondly, surfaces of the relevant climate variables (Supplementary Figure S1), which were used as inputs for the anthocyanin and TA models, were constructed from the downscaled GCM climate data. Thirdly, surfaces for concentrations of anthocyanin and TA were generated by driving the climate surfaces by the relevant parameter estimates of the berry trait-climate models (Barnuud et al. 2013, see illustration in Supplementary Figure S2). Finally, the berry anthocyanin and TA surfaces were extracted within the WA GIs boundaries, and relevant statistics were derived from pixels that are located within a wine GI boundary. These processes were carried out for the baseline (1975-2005) and future climate conditions for 2030, 2050 and 2070 derived from the csiro $\mathrm{mk} 35$ and miroc3 2 medres GCMs, to analyse changes in concentrations of berry anthocyanin and TA across temporal and spatial dimensions.

\section{Results}

Modelled grape maturity dates

\section{Under baseline climate conditions}

For the climate variables evaluated, considering all three varieties, the average temperature between October and February inclusive was the best predictor of maturity dates. Depending on variety, between $88 \%$ and $94 \%$ of the variations in maturity dates across the WA GIs were accounted for using this climate variable (Table 1). For the baseline climate conditions, the patterns of the modelled maturity dates of the three varieties showed considerable temporal spread and geographical detail reflective of the temperature gradients across the wine regions (Figs. 2, 3a, 4, and 5a). For example, Cabernet Sauvignon and Shiraz varieties reached the common maturity (22 ${ }^{\circ}$ Brix TSS) about 10 February in the warmer Swan Districts GI, but in the cooler southern regions the same levels of maturity were attained by the middle of April (Figs. 3a, 4, and 5a). In a few elevated places in the Stirling Range, Cabernet Sauvignon and Shiraz maturities extended to the beginning of May (Figs. 3a-5a). Similarly, Chardonnay reached the $22{ }^{\circ}$ Brix TSS during late January in the northern regions, but it took more than 2 months additional time to reach the same maturity level in the cooler southern regions (Figs. 3a, 4, and 5a). Maturity date determinations were also carried out using the accumulated biologically effective day degree (BEDD) concept of Gladstones (1992), which was used previously to assess climate change impact on growing season length across all the Australian GIs (Hall and Jones 2009). However, at least for the baseline climate conditions, the maturity patterns obtained using the BEDD approach were temporally more compacted (and regionally less detailed) than the empirically determined results (Figure S3, Barnuud 2012). This is, however, expected since the BEDD approach is not designed for predicting berry maturity at a specific level of ripening, in this case $22^{\circ}$ Brix TSS. Therefore, in this work, the regression method based on the October to February average temperatures was used for estimating future maturity dates $(2030,2050$ and 2050).

\section{Under projected climate conditions}

For all three varieties, the projected effects of climate change on the median maturity dates $\left(22^{\circ}\right.$ Brix TSS) are likely to be more pronounced in the southern than in the northern wine regions under both the least (miroc3 2 medres) and most warming (csiro mk3 5 ) scenarios. For example, compared to the baseline maturity dates, by 2070 , under the most warming climate scenario, all varieties are projected to reach $22^{\circ}$ Brix TSS 6-7 weeks earlier in the southern wine regions (Figs. 2, 3g, 4, 5g). By contrast, the same varieties will reach 
Table 1 Empirical models describing the relationships between the average temperature during the October to February period and maturity dates $\left[22^{\circ}\right.$ Brix total soluble solids (TSS)]. Note that the dates are counted from 1 January

\begin{tabular}{|c|c|c|c|c|}
\hline \multirow[b]{2}{*}{ Variety } & \multirow[b]{2}{*}{ Models ${ }^{\mathrm{c}}$} & \multicolumn{2}{|c|}{ Model coefficients, and standard errors (in parentheses) } & \multirow[b]{2}{*}{ Adj_ $r^{2}$} \\
\hline & & $a$ & $b$ & \\
\hline Cabernet Sauvignon & $y=a \times x^{b}$ & $62.55 * *(11.63)$ & $-2.49 * * *(0.17)$ & 0.94 \\
\hline Shiraz & $y=a \times x^{b}$ & $79.58 *(22.6)$ & $-2.72 * *(0.26)$ & 0.92 \\
\hline Chardonnay & $y=a \times x+b$ & $-5.39 * * *(0.53)$ & $19.85 * *(1.56)$ & 0.88 \\
\hline
\end{tabular}

* $P<0.01$, ** $P<0.001$, *** $P<0.0001$

${ }^{\mathrm{c}} y=$ day of year when berries reach $22^{\circ}$ Brix TSS maturity, $x=$ October to February average temperature $\left({ }^{\circ} \mathrm{C}\right)$. Both $x$ and $y$ are in natural $\log$-scale

Fig. 2 Modelled median grape maturity dates at $22^{\circ}$ Brix total soluble solids (TSS) under current and projected future climate. miroc3 2 medres and csiro_mk 3 - 5 models represent the least and most warming climate assumptions, respectively, across the wine regions. a Cabernet Sauvignon, b Shiraz, c Chardonnay
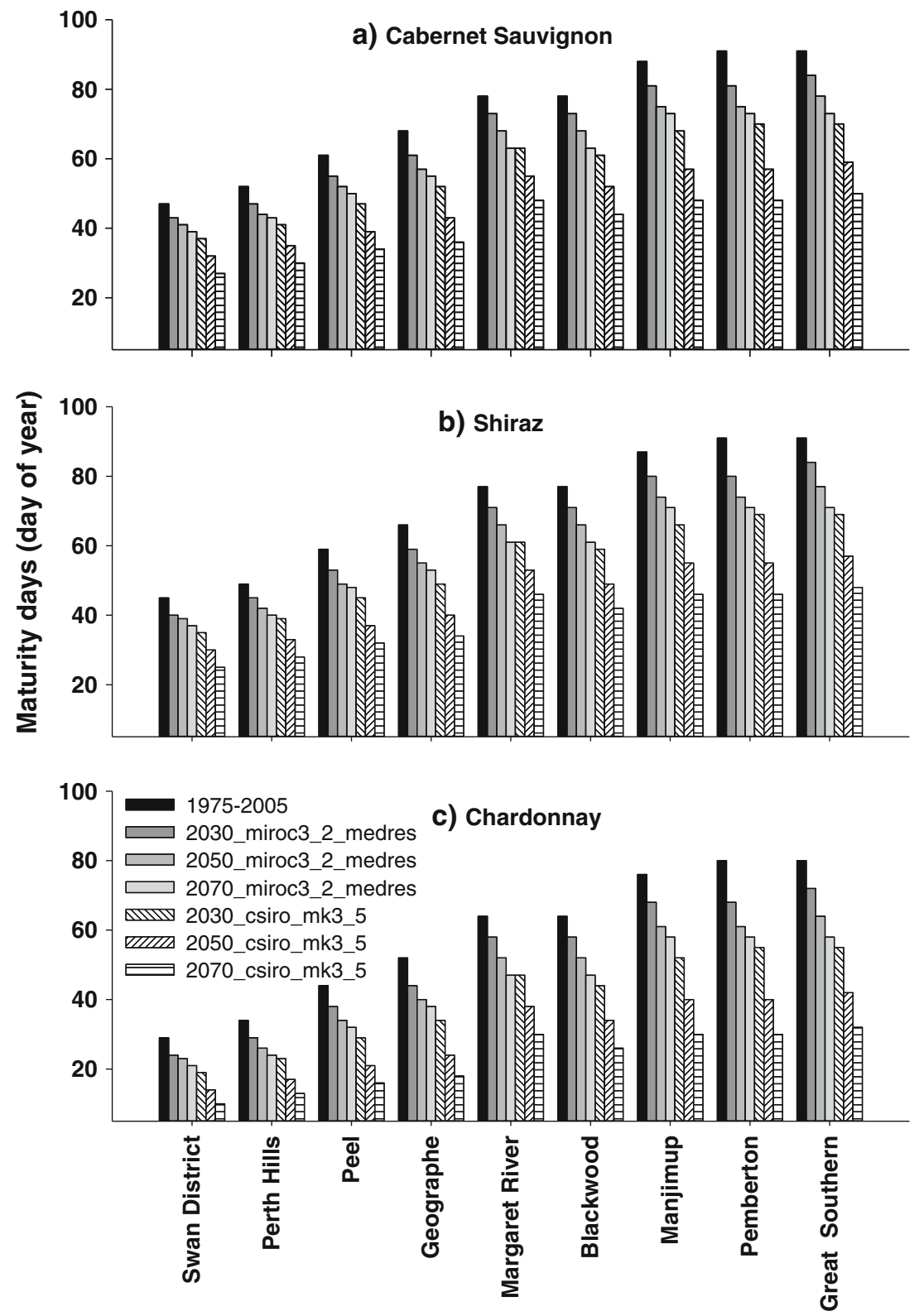

The Western Australian Wine regions 


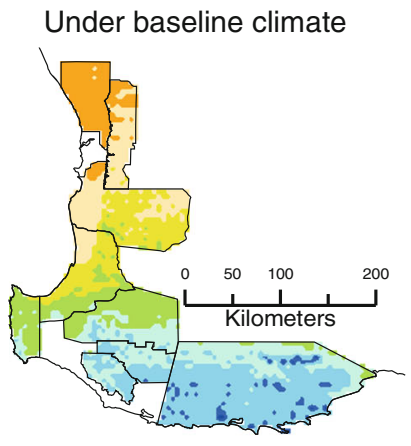

a) $1975-2005$

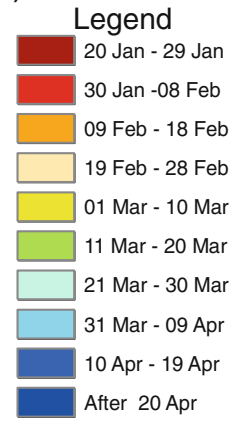

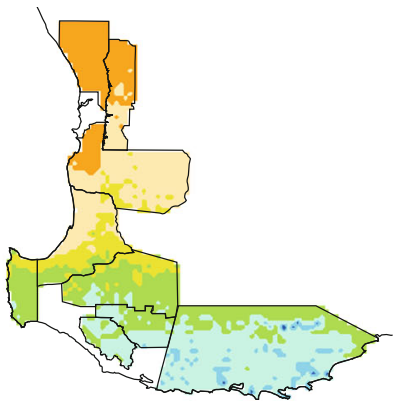

b) 2030 miroc3_2_medres

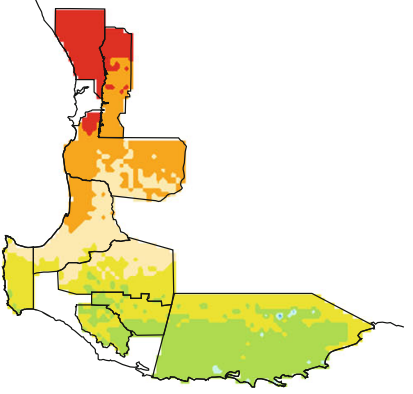

e) 2030 csiro_mk3_5
Future projections

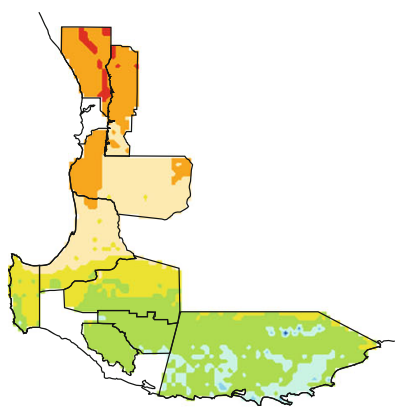

c) 2050miroc3_2_medres

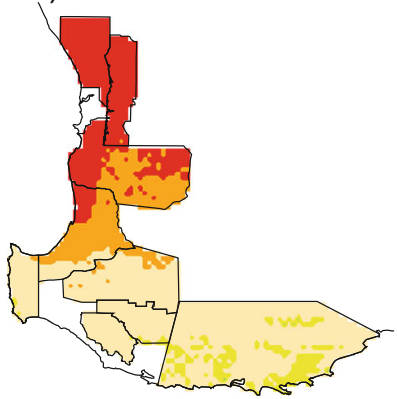

f) 2050 csiro_mk3_5

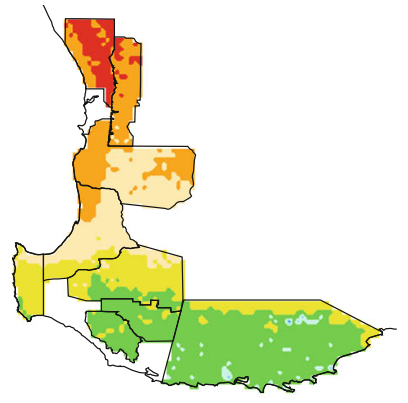

d) 2070miroc3_2_medres

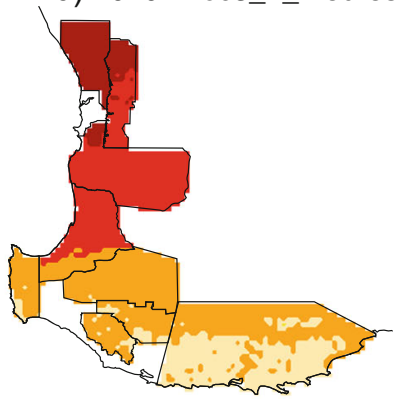

g) 2070 csiro_mk3_5

Fig. 3 Modelled current and future Cabernet Sauvignon maturity dates (to $22^{\circ}$ Brix TSS) based on average October-February temperature. a Under current climate conditions; $\mathbf{b}-\mathbf{d}$ using projections from miroc3_2_medres SRES A2; e-g using projections from csiro_mk3_5 SRES A2

the same common maturity about 3 weeks early in the warmer northern regions compared to the maturities under the baseline climate, indicating uneven advancement of grape maturities across the regions under climate change (Figs. 2, 3g, 4, 5g).

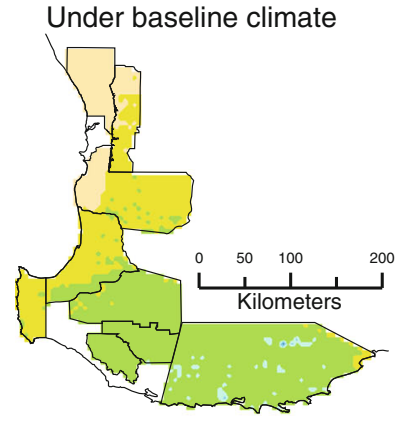

a) $1975-2005$ Legend

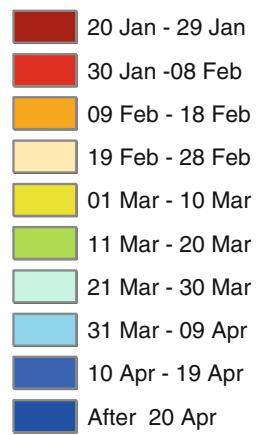

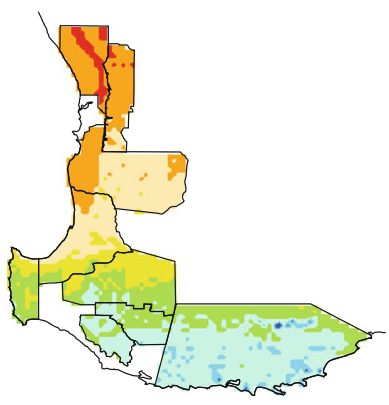

b) 2030miroc3_2_medres

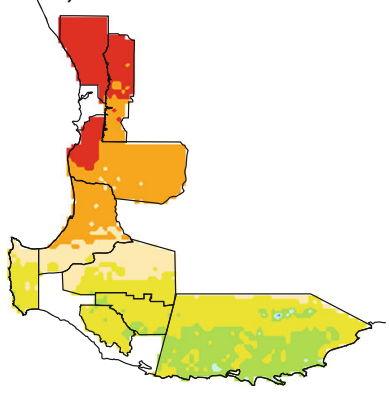

e) 2030 csiro_mk3_5

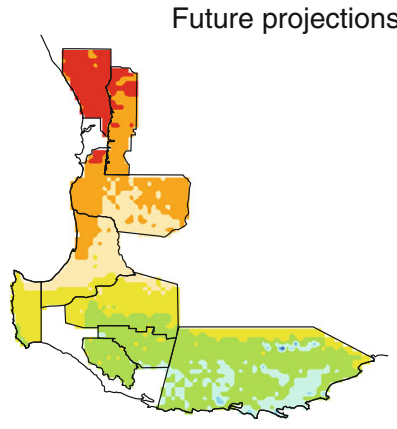

c) 2050miroc3_2_medres

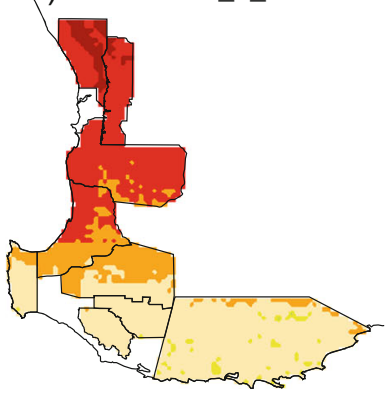

f) 2050 csiro_mk3_5

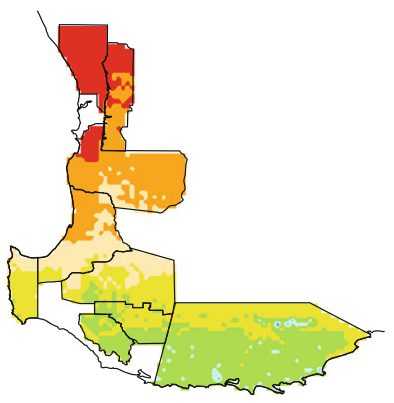

d) 2070miroc3_2_medres

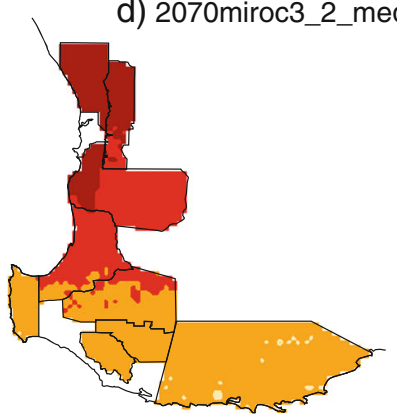

g) 2070 csiro_mk3_5a

Fig. 4 Modelled current and future Shiraz maturity dates (to $22{ }^{\circ}$ Brix TSS) based on average October-February temperature. a Under baseline climate conditions; $\mathbf{b}-\mathbf{d}$ using projections from miroc3_2_medres SRES A2; $\mathbf{e}-\mathbf{g}$ using projections from csiro_mk3_5 SRES A2 


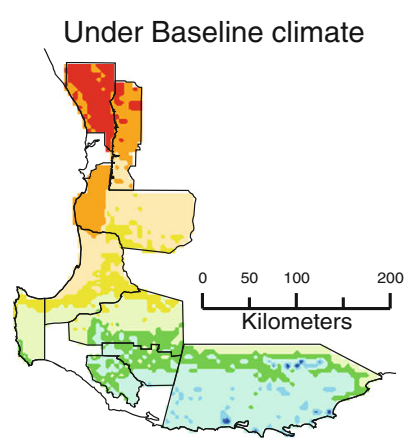

a) $1975-2005$

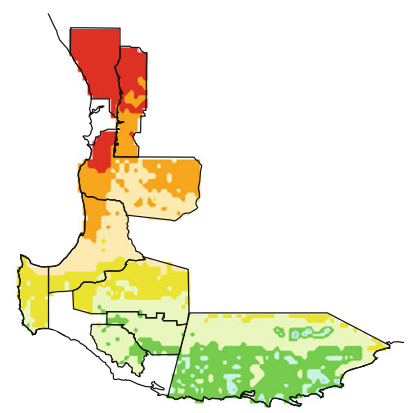

b) 2030 miroc3_2_medres

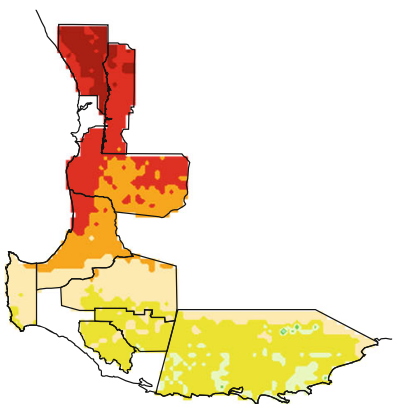

e) 2030 csiro_mk3_5

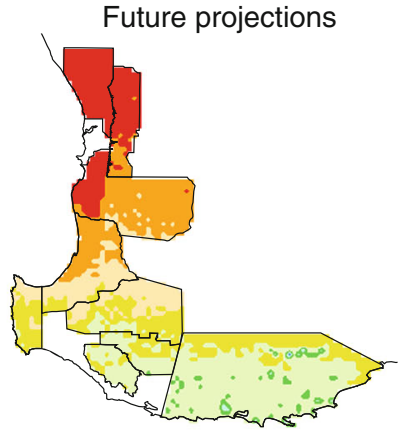

c) 2050 miroc3_2_medres

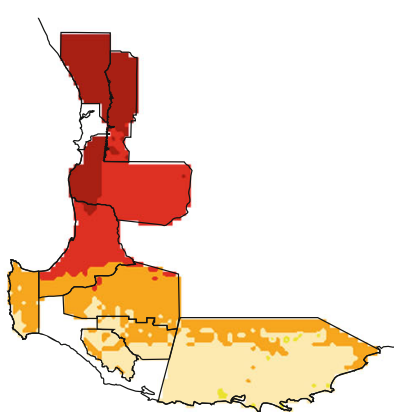

f) 2050 csiro_mk3_5

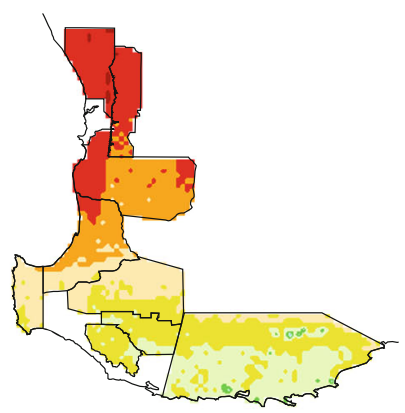

d) 2070 miroc3_2_medres

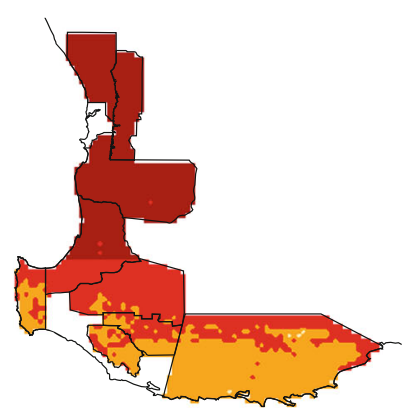

g) 2070 Csiro_mk3_5

Fig. 5 Modelled current and future Chardonnay maturity dates (to $22^{\circ}$ Brix TSS) based on average October-February temperature. a Under current climate conditions; $\mathbf{b}-\mathbf{d}$ based on projections from miroc3_2_medres SRES A2; $\mathbf{e}-\mathbf{g}$ based on projections from csiro_mk3_5 SRES A2

Under the least warming climate scenario, all three varieties will reach the same common maturity about a week earlier by 2070 in warmer districts, while in cooler southern regions, for example in the Great Southern region it will be about 18, 20, and 22 days earlier, respectively, for Cabernet Sauvignon, Shiraz, and Chardonnay (Figs. 2, 3d, 4, 5d).

Projected impacts of climate change on anthocyanin concentrations

Compared to the levels for the baseline period centred on 1990, Cabernet Sauvignon median anthocyanin concentrations are projected to decrease progressively with time. However, the magnitudes of reductions and the regional responses are dependent on the warming scenario (GCM). Under the most warming scenario (csiro_mk3_5), the median anthocyanin concentrations in the northern regions are projected to decline to two-thirds of the current level (e.g. for the Swan Districts region, from 1.34 to $0.90 \mathrm{mg} / \mathrm{g}$ ) while up to $18 \%$ reductions are projected for the southern regions by 2070 (Table 2, Fig. 6g) indicating uneven changes across regions. By contrast, impacts of the least warming scenario (miroc3_2_medres) on the Cabernet Sauvignon anthocyanins concentrations will likely be spatially similar, while the magnitude of reductions are projected to be three to four times less than that of high the warming scenario (Table 2, Fig. 6d).

For Shiraz berries, reduction in the median anthocyanin concentrations is projected to be $18 \%$ by 2070 for the Swan Districts region under the most warming scenario compared to the levels under the baseline climate conditions (Table 2, Fig. $7 \mathrm{~g}$ ). The losses of anthocyanins are likely to be smaller in the cooler southern regions, reaching a $9 \%$ decline in the Margaret River region by 2070 (Table 2). Under the least warming scenario, Shiraz anthocyanin concentrations are projected to decline only marginally (about 3-4\%) by 2070 across the wine regions (Fig. 7d, Table 2).

\section{Climate change impact on titratable acidity}

Under the baseline climate conditions, Cabernet Sauvignon TA levels exhibit marked spatial patterns (Fig. 8). These levels and trends are largely preserved under the least warming climate scenario (miroc3_2_medres), including up to the 2070 outlook period. In contrast, under the highest warming model scenario, median TA levels across all wine regions are projected to drop, with the effect increasing over time (Table 3). In particular, the north eastern parts of the Swan Districts, Perth Hills, and inland parts of the Peel regions are 
Table 2 Current and projected median anthocyanin concentrations (mg malvidin-3-O-glucoside equivalents /g berry fresh weight) at common maturity $\left(22^{\circ}\right.$ Brix TSS) across the Western Australian (WA) wine regions

\begin{tabular}{|c|c|c|c|c|c|c|c|c|c|c|c|}
\hline \multirow[t]{2}{*}{ Variety } & \multirow{2}{*}{\multicolumn{2}{|c|}{$\begin{array}{l}\text { Time and } \\
\text { warming }^{\mathrm{a}} \\
\text { ranges }^{\mathrm{a}}\end{array}$}} & \multicolumn{9}{|l|}{ Wine region } \\
\hline & & & Swan District & Perth Hills & Peel & Geographe & Margaret River & Blackwood & Manjimup & Pemberton & Great Southern \\
\hline \multirow{7}{*}{$\begin{array}{l}\text { Cabernet } \\
\text { Sauvignon }\end{array}$} & \multicolumn{2}{|l|}{ Current } & 1.34 & 1.37 & 1.46 & 1.54 & 1.71 & 1.64 & 1.72 & 1.76 & 1.78 \\
\hline & \multirow[t]{2}{*}{2030} & 1 & 1.30 & 1.33 & 1.42 & 1.51 & 1.68 & 1.60 & 1.69 & 1.73 & 1.75 \\
\hline & & 2 & 1.18 & 1.22 & 1.32 & 1.40 & 1.62 & 1.52 & 1.61 & 1.64 & 1.67 \\
\hline & \multirow[t]{2}{*}{2050} & 1 & 1.26 & 1.29 & 1.38 & 1.47 & 1.64 & 1.57 & 1.65 & 1.69 & 1.71 \\
\hline & & 2 & 1.05 & 1.10 & 1.19 & 1.28 & 1.54 & 1.42 & 1.51 & 1.54 & 1.57 \\
\hline & \multirow[t]{2}{*}{2070} & 1 & 1.23 & 1.26 & 1.35 & 1.44 & 1.62 & 1.54 & 1.63 & 1.67 & 1.68 \\
\hline & & 2 & 0.90 & 0.97 & 1.06 & 1.14 & 1.45 & 1.31 & 1.40 & 1.44 & 1.46 \\
\hline \multirow[t]{7}{*}{ Shiraz } & \multicolumn{2}{|l|}{ Current } & 1.35 & 1.36 & 1.41 & 1.46 & 1.55 & 1.51 & 1.55 & 1.57 & 1.59 \\
\hline & \multirow[t]{2}{*}{2030} & 1 & 1.33 & 1.34 & 1.39 & 1.44 & 1.53 & 1.49 & 1.54 & 1.56 & 1.57 \\
\hline & & 2 & 1.26 & 1.29 & 1.34 & 1.38 & 1.50 & 1.45 & 1.49 & 1.51 & 1.53 \\
\hline & \multirow[t]{2}{*}{2050} & 1 & 1.30 & 1.32 & 1.37 & 1.42 & 1.51 & 1.47 & 1.52 & 1.54 & 1.55 \\
\hline & & 2 & 1.19 & 1.22 & 1.27 & 1.31 & 1.45 & 1.39 & 1.44 & 1.46 & 1.47 \\
\hline & \multirow[t]{2}{*}{2070} & 1 & 1.29 & 1.31 & 1.35 & 1.40 & 1.50 & 1.46 & 1.50 & 1.52 & 1.53 \\
\hline & & 2 & 1.11 & 1.14 & 1.20 & 1.24 & 1.41 & 1.33 & 1.38 & 1.40 & 1.41 \\
\hline
\end{tabular}

${ }^{\text {a }}$ Warming ranges: 1 low warming condition across wine regions projected by miroc 32 __medres model, 2 high warming condition across the wine regions projected by csiro_mk_5 model

projected to experience the largest decline, up to $12 \%$ by 2070 (Fig. 8, Table 3).

The modelled Shiraz TA indicates reductions across most of the wine GIs with the highest TA losses $(15 \%)$ projected for the Peel and the Great Southern GIs by 2070 under highest warming projection. Interestingly, consistently small reductions in the median TA are projected for the central regions, especially the Margaret River region $-3 \%$ and $-7 \%$ by 2050 respectively under low and high warming scenarios (Table 3, Fig. 9). Spatially, inland parts of the Peel region are likely to experience

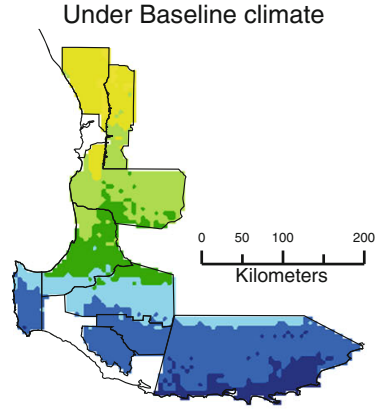

a) $1975-2005$

Legend $(\mathrm{mg} / \mathrm{g})$

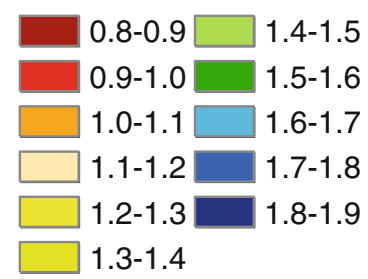

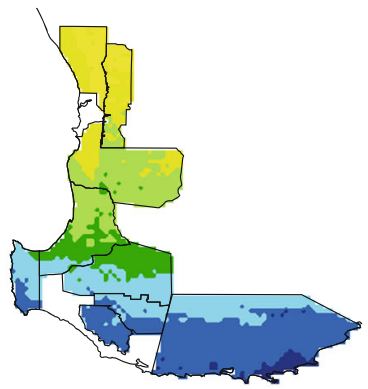

b) 2030 miroc3_2_medres

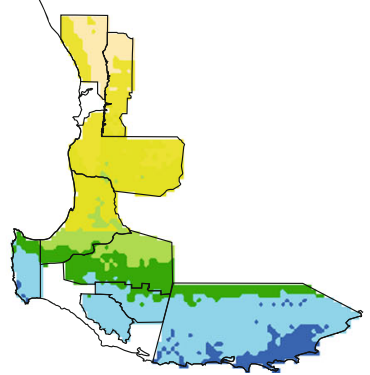

e) 2030 csiro_mk3_5

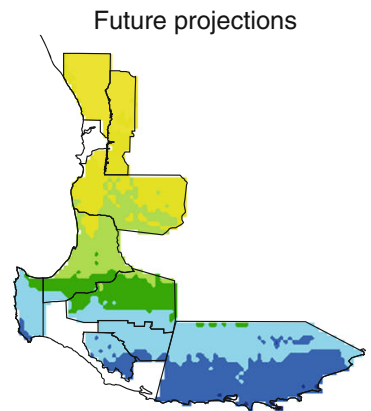

c) 2050 miroc3_2_medres

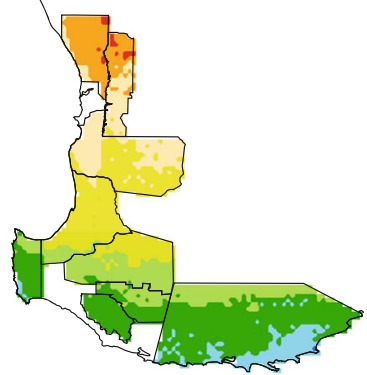

f) 2050 csiro_mk3_5

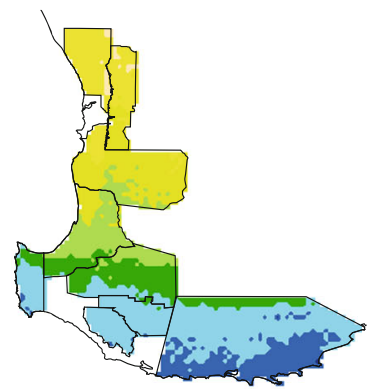

d) 2070 miroc3_2_medres

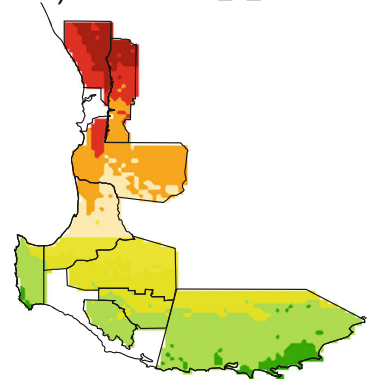

g) 2070 csiro_mk3_5

Fig. 6 Current and projected Cabernet Sauvignon anthocyanin concentration (mg malvidin-3-O-glucoside equivalents per g berry fresh weight at common maturity, $22{ }^{\circ}$ Brix TSS) based on mean January temperature 


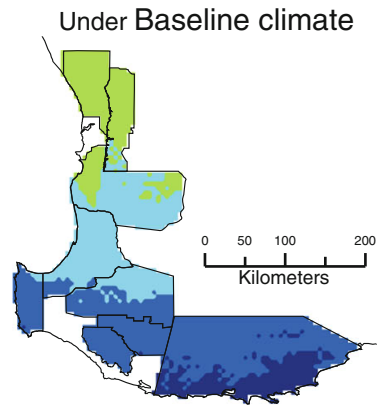

a) $1975-2005$

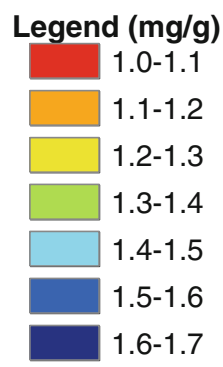

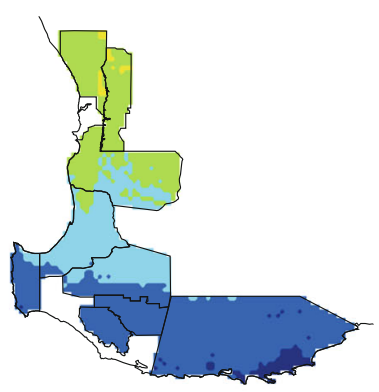

b) 2030 miroc3_2_medres

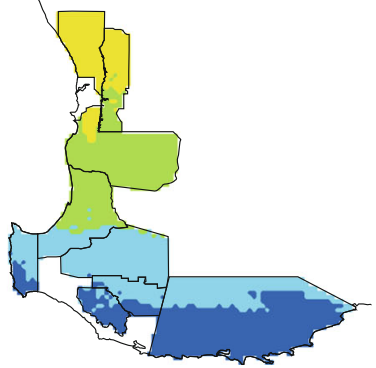

e) 2030 csiro_mk3_5

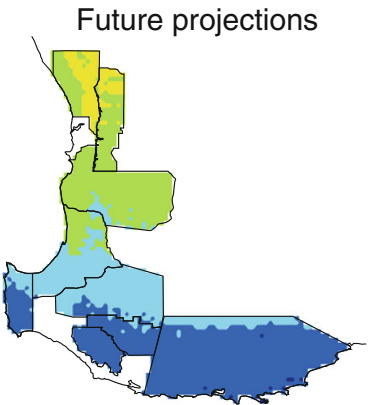

c) 2050 miroc3_2_medres

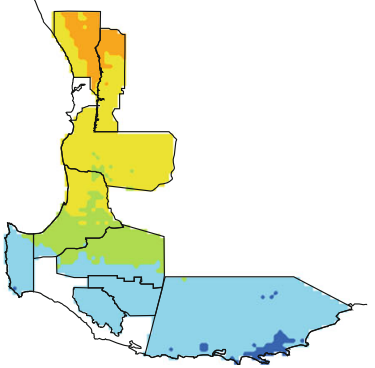

f) 2050 csiro_mk3_5

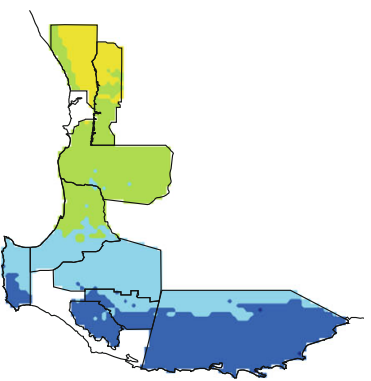

d) 2070 miroc3_2_medres

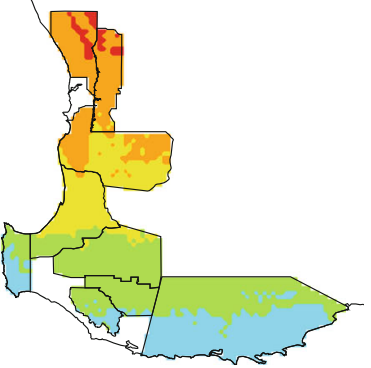

g) 2070 csiro_mk3_5

Fig. 7 Current and projected Shiraz anthocyanin concentration (mg malvidin-3-O-glucoside equivalents per gram berry fresh weight at a common maturity, $22^{\circ}$ Brix TSS) driven by mean January temperature

the lowest levels of Shiraz TA, declining from the current range of $5.5-6.0(\mathrm{~g} / \mathrm{L})$ to $5.0-5.5(\mathrm{~g} / \mathrm{L})$ by 2050 under the highest warming projection (Fig. 9).

Under both the least and most warming scenarios, the Chardonnay TA model projects a decline in median TA for all the WA wine GIs, with the TA loss generally increasing steadily with each outlook period (Table 3 ). The largest drops in the median TA levels were between $40 \%$ and $42 \%$ for the Swan Districts, Perth Hills, Peel and the northeast Geographe regions by 2070, under the most warming scenario (Table 3, Fig. 10). Under the same warming scenario, median TA levels of Chardonnay in the southern wine regions are projected to

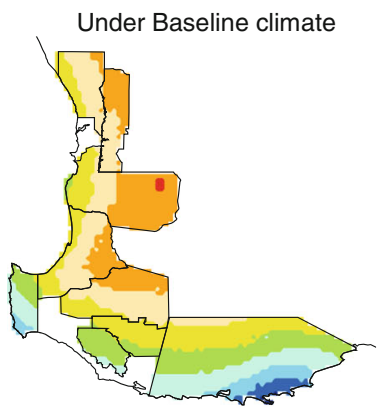

a) $1975-2005$

Legend ( $g / L)$

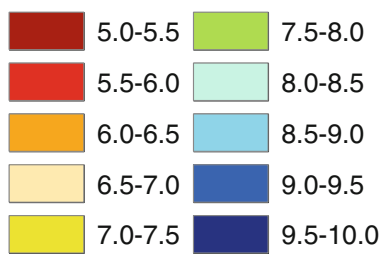

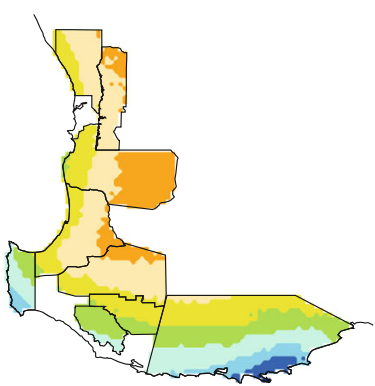

b) 2030 miroc3_2_medres

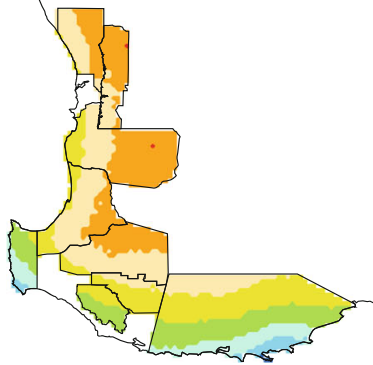

e) 2030 csiro_mk3_5

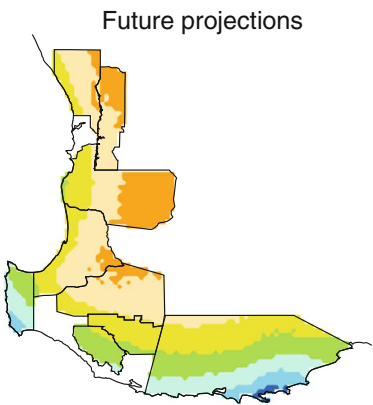

c) 2050miroc3_2_medres

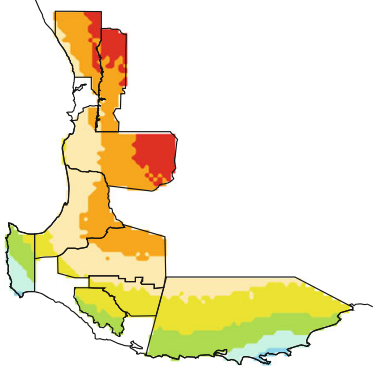

f) 2050 csiro_mk3_5

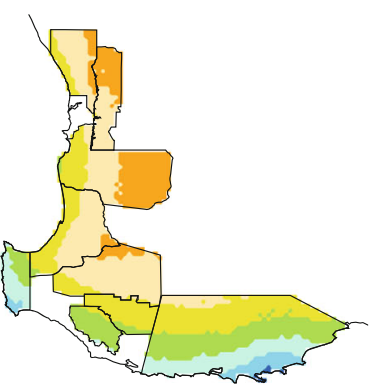

d) 2070 miroc3_2_medres

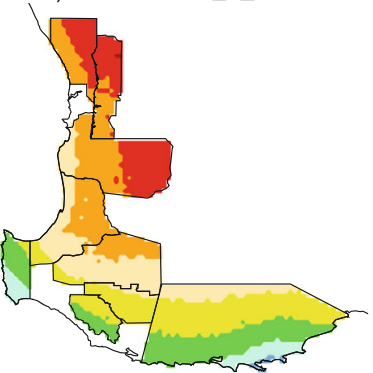

g) 2070 csiro_mk3_5

Fig. 8 Current and projected Cabernet Sauvignon titratable acidity (TA: grams tartaric acid equivalents/litre juice, at common maturity of $22{ }^{\circ}$ Brix TSS) driven by growing season diurnal range and ripening period minimum temperature 
Table 3 Current and projected median titratable acidity (TA; grams tartaric acid equivalents/litre grape juice) at common maturity (22 ${ }^{\circ}$ Brix TSS) across the WA wine regions

\begin{tabular}{|c|c|c|c|c|c|c|c|c|c|c|c|}
\hline \multirow[t]{2}{*}{ Variety } & \multirow{2}{*}{\multicolumn{2}{|c|}{$\begin{array}{l}\text { Time and } \\
\text { warming } \\
\text { ranges }^{\mathrm{a}}\end{array}$}} & \multicolumn{9}{|l|}{ Wine region } \\
\hline & & & Swan District & Perth Hills & Peel & Geographe & Margaret River & Blackwood & Manjimup & Pemberton & Great Southern \\
\hline \multirow{7}{*}{$\begin{array}{l}\text { Cabernet } \\
\text { Sauvignon }\end{array}$} & \multicolumn{2}{|l|}{ Current } & 6.81 & 6.48 & 6.35 & 6.75 & 8.09 & 6.62 & 7.29 & 7.79 & 7.86 \\
\hline & \multirow[t]{2}{*}{2030} & 1 & 6.88 & 6.62 & 6.45 & 6.83 & 8.14 & 6.72 & 7.32 & 7.87 & 7.86 \\
\hline & & 2 & 6.53 & 6.37 & 6.33 & 6.73 & 7.97 & 6.58 & 7.09 & 7.54 & 7.52 \\
\hline & \multirow[t]{2}{*}{2050} & 1 & 6.76 & 6.55 & 6.49 & 6.86 & 8.06 & 6.69 & 7.25 & 7.73 & 7.69 \\
\hline & & 2 & 6.18 & 6.06 & 6.20 & 6.60 & 7.92 & 6.57 & 7.07 & 7.46 & 7.38 \\
\hline & \multirow[t]{2}{*}{2070} & 1 & 6.73 & 6.51 & 6.52 & 6.87 & 8.08 & 6.70 & 7.23 & 7.71 & 7.66 \\
\hline & & 2 & 5.98 & 5.90 & 6.06 & 6.51 & 7.89 & 6.61 & 7.10 & 7.49 & 7.42 \\
\hline \multirow[t]{7}{*}{ Shiraz } & \multicolumn{2}{|l|}{ Current } & 7.25 & 6.85 & 6.92 & 7.56 & 9.77 & 7.27 & 8.52 & 9.73 & 9.45 \\
\hline & \multirow[t]{2}{*}{2030} & 1 & 7.27 & 6.89 & 6.91 & 7.53 & 9.78 & 7.24 & 8.45 & 9.62 & 9.32 \\
\hline & & 2 & 6.89 & 6.49 & 6.47 & 7.14 & 9.48 & 6.88 & 8.03 & 9.12 & 8.79 \\
\hline & \multirow[t]{2}{*}{2050} & 1 & 7.12 & 6.72 & 6.72 & 7.38 & 9.57 & 7.09 & 8.28 & 9.38 & 9.09 \\
\hline & & 2 & 6.35 & 5.92 & 5.88 & 6.58 & 9.07 & 6.37 & 7.48 & 8.51 & 8.17 \\
\hline & \multirow[t]{2}{*}{2070} & 1 & 7.03 & 6.62 & 6.60 & 7.28 & 9.45 & 6.99 & 8.16 & 9.22 & 8.93 \\
\hline & & 2 & 6.44 & 5.95 & 5.89 & 6.57 & 9.10 & 6.35 & 7.41 & 8.38 & 7.99 \\
\hline \multirow[t]{7}{*}{ Chardonnay } & \multicolumn{2}{|l|}{ Current } & 9.08 & 8.51 & 8.43 & 8.36 & 10.17 & 8.22 & 9.35 & 9.97 & 11.27 \\
\hline & \multirow[t]{2}{*}{2030} & 1 & 9.15 & 8.77 & 8.45 & 8.37 & 10.29 & 8.21 & 9.29 & 9.87 & 11.13 \\
\hline & & 2 & 7.96 & 7.66 & 7.34 & 7.40 & 9.67 & 7.50 & 8.17 & 8.65 & 9.74 \\
\hline & \multirow[t]{2}{*}{2050} & 1 & 8.79 & 8.44 & 8.13 & 8.14 & 10.29 & 8.22 & 8.99 & 9.54 & 10.68 \\
\hline & & 2 & 6.83 & 6.58 & 6.39 & 6.47 & 9.06 & 6.54 & 7.47 & 8.01 & 9.14 \\
\hline & \multirow[t]{2}{*}{2070} & 1 & 8.72 & 8.36 & 8.01 & 8.11 & 10.33 & 8.25 & 9.02 & 9.51 & 10.62 \\
\hline & & 2 & 5.23 & 5.08 & 5.06 & 5.33 & 8.45 & 5.80 & 6.64 & 7.19 & 8.32 \\
\hline
\end{tabular}

${ }^{\mathrm{a}}$ Warming ranges as in Table 2

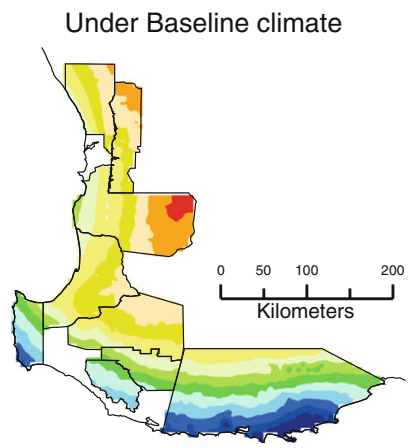

a) $1975-2005$

\section{Legend ( $g / L)$}

\begin{tabular}{|c|c|}
\hline $5.0-5.5$ & $8.5-9.0$ \\
\hline $5.5-6.0$ & $9.0-9.5$ \\
\hline $6.0-6.5$ & $9.5-10.0$ \\
\hline $6.5-7.0$ & $10.0-10.5$ \\
\hline $7.0-7.5$ & $10.5-11.0$ \\
\hline $7.5-8.0$ & $11.0-11.5$ \\
\hline $8.0-8.5$ & $11.5-12.0$ \\
\hline
\end{tabular}

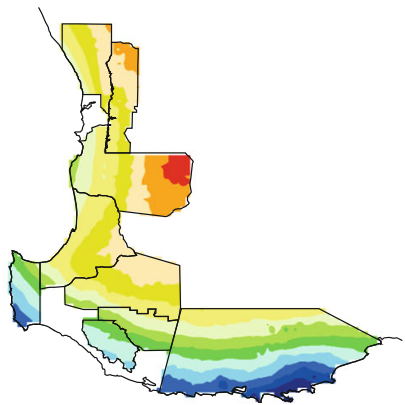

b) 2030 miroc3_2_medres

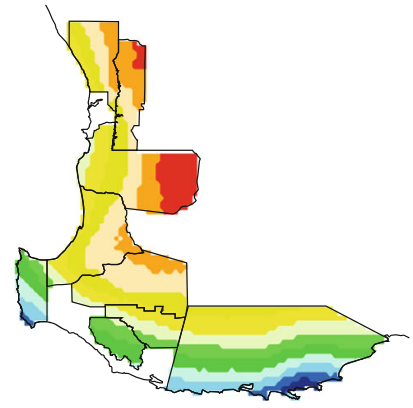

e) 2030 csiro_mk3_5
Future projections

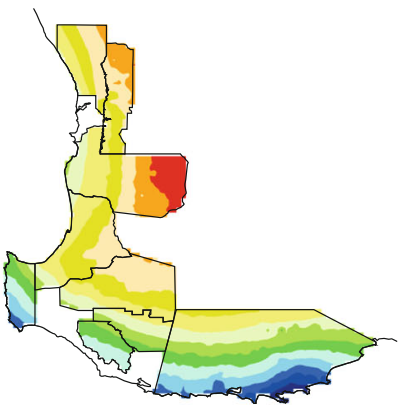

C) 2050 miroc3_2_medres

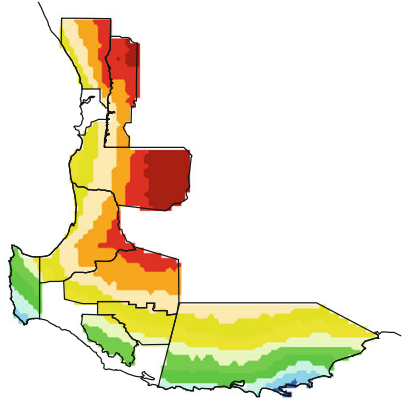

f) 2050 csiro_mk3_5

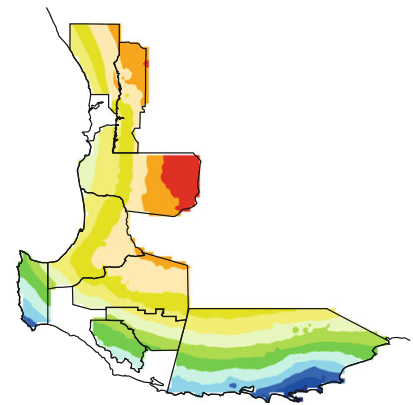

d) 2070 miroc3_2_medres

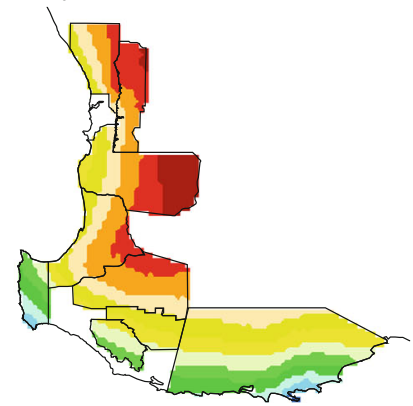

g) 2070 csiro_mk3_5

Fig. 9 Current and projected Shiraz TA (as in Fig. 8) driven by October to February diurnal range and growing season total rainfall 

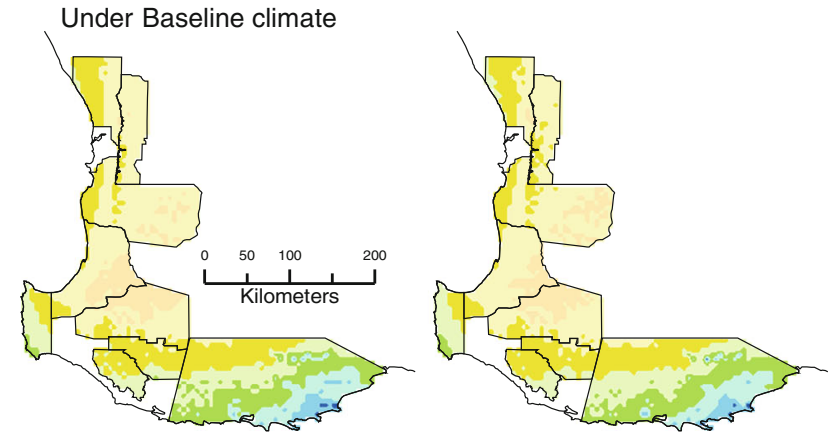

a) $1975-2005$

Legend (g/L)
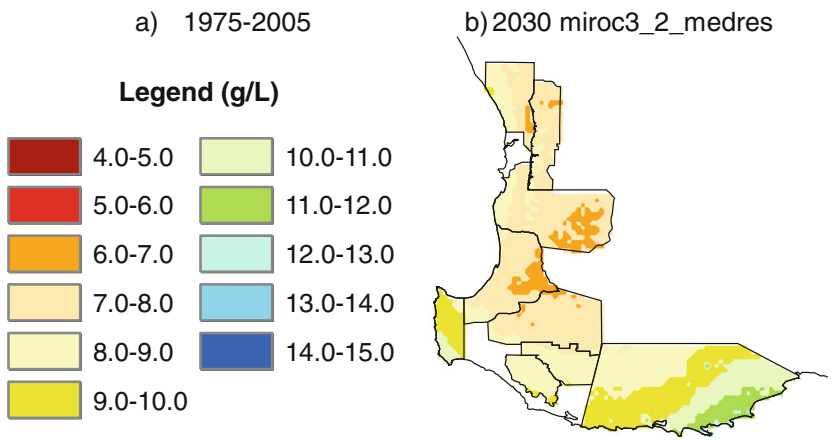

e) 2030 csiro_mk3_5

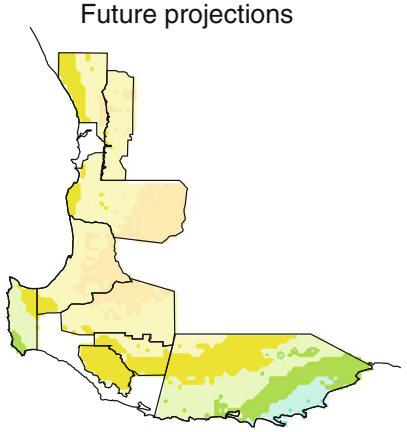

c) 2050 miroc3_2_medres

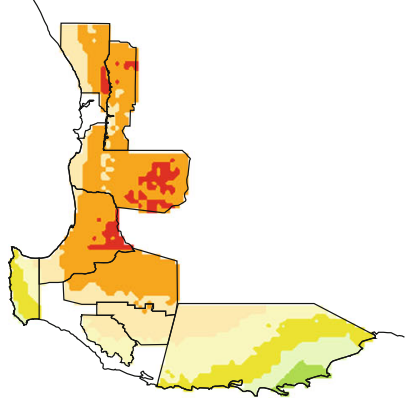

f) 2050 csiro_mk3_5

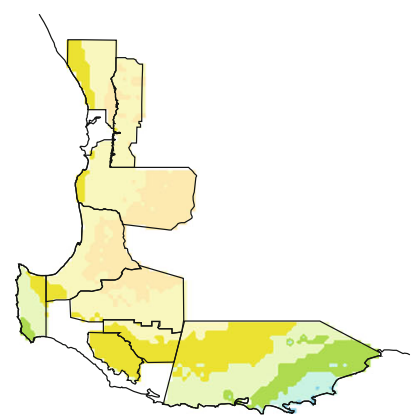

d) 2070 miroc3_2_medres

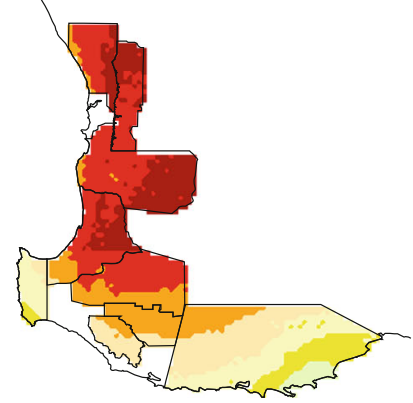

g) 2070 csiro_mk3_5

Fig. 10 Current and projected Chardonnay TA (as in Fig. 8) driven by February diurnal range, ripening period minimum temperature, and average radiation in October

drop by about $30 \%$. Levels of Chardonnay TA at maturity are projected to be least impacted by climate change in the Margaret River region - the largest losses being about $2 \%$ and $17 \%$ of the baseline TA levels by 2070 , respectively, under the least and most warming scenarios (Table 3, Fig. 10).

\section{Discussion}

Projected maturity dates

The modelled results indicate that while there will be advancement of maturity dates for the three varieties across all the WA GIs, these will be spatially asymmetric, being considerably greater in the currently cool southern wine regions than in the warm northern regions. This is in accord with the thesis that, for temperature driven events, greater responses to warming would be expected in cooler regions where temperature exerts greater limitations than in warmer regions (Bradley et al. 1999; Webb et al. 2007) as well as with the BEDD concept of Gladstones (1992), which postulates that high average temperatures $\left(>19^{\circ} \mathrm{C}\right)$ are ineffective for grapevine physiology. The general tends of the modelled maturity dates, i.e. relatively greater impact of warming in the cooler than the warmer regions, are also broadly consistent with earlier results (Webb et al. 2007; Hall and Jones 2009). Notwithstanding the similarity in the overall trends, under the most warming climate scenario, the projected median maturity dates for Cabernet Sauvignon from the current study are generally earlier than the maturity dates that were derived from the BEDD accumulation approach (Hall and Jones 2009). This disparity is not surprising since the current study modelled the maturity dates at constant $22{ }^{\circ} \mathrm{Brix}$ TSS, while the BEDD maturity concept is based on practical observations for making dry or semi-sweet wines without measurable characteristics for the maturity (Gladstones 1992). In practise, this means grapes tend to be left on vines beyond the $22{ }^{\circ}$ Brix TSS maturity to attain fully developed flavour unless needed for making special style wines such as sparkling wine.

Differences in maturity date projections between the current and earlier studies are relatively small when comparisons are made at similar maturity level. For example, at $22{ }^{\circ}$ Brix TSS maturity, there was a difference of only 2 days between the projected Cabernet Sauvignon maturity dates from this study, under the least warming condition, and the harvest dates reported by Webb et al. (2007) using the VineLOGIC simulation model for the Margaret River GI by 2030 and 2050. Similarly, the projected Chardonnay maturity dates from this study were only slightly earlier (up to 7 days) than those projected by Webb et al. (2007) for the 2030 and 2050 periods.

The projected maturity dates for Chardonnay are consistently earlier than for Cabernet Sauvignon and Shiraz at the 
same level of maturity. This pattern is consistent with the biology of these varieties having different thermal time requirements to reach maturity (Gladstones 1992). Although the maturity "rankings" of these three varieties seem to be preserved, the projections indicate regional homogenisation (compaction) of maturity dates. While this is so under the least and most warming scenarios, the compressions of the maturity dates across regions and varieties are particularly acute under the most warming scenario. The potential impact that this may have on harvest and winery logistics has been discussed in Webb et al. (2007). In the sections below, potential effects on berry composition, in particular anthocyanin and TA are considered.

Trends in anthocyanin concentrations and implications for wine quality

Anthocyanin and TA are two aspects of berry composition that are integral to the production of premium wines. Controlled environment (Kliewer and Torres 1972; Mori et al. 2007) and climate gradient studies (Barnuud et al. 2013) have shown that these berry attributes are sensitive to climate. This study builds on our earlier work (Barnuud et al. 2013) to provide the first regional-scale climate impact assessment on berry colour and acidity for three of the major wine grape varieties.

Under baseline climate conditions, berry anthocyanin concentrations of both Cabernet Sauvignon and Shiraz show increasing trends from the warmer northern to the cooler southern regions. For future climate conditions, while regional anthocyanin gradients will likely exist, the magnitude of impacts on anthocyanin concentrations may vary considerably depending on the magnitudes of warming (GCM) projections. In particular, under the most warming projection (csiro_mk3_5), a distinct impact is a spatiotemporal (progressively southwards) shift of the currently observed anthocyanin concentrations for most of the wine regions. The results also indicate that, without the use of effective adaptation measures, in the presently warm Perth Hills and Swan Districts regions, anthocyanins are projected to drop to new-low levels in almost all of the three outlook periods. For each of the other regions, in each outlook period, their median anthocyanin concentrations are predicted to decline to the levels of the preceding projection period for the adjoining region to the north. For example, by 2030, Cabernet and Shiraz anthocyanin concentrations are projected to be similar to the levels that are observed currently in the adjacent warmer areas to the north; while the levels in 2050 will likely mirror those of the neighbouring regions to the north in 2030 , and so on.

Although berry anthocyanin concentrations are projected to decrease in both varieties (especially under the csiro $\mathrm{mk} 3$ _ 5 climate projections), the relative impact is greater in Cabernet Sauvignon than in Shiraz (e.g. by 2070 across regions average reductions of $27 \%$ vs $13 \%$, relative to the respective concentrations for baseline period). While differences in rates of phenological progression, and hence timing of the ripening period vis-à-vis the warmest period of the growing season can contribute to the above response, this varietal difference is largely reflective of the relatively greater decline in anthocyanin concentration of Cabernet Sauvignon than of Shiraz berries per degree of warming during the veraison period (Barnuud et al. 2013). The mechanism that underlies this differential response, however, is unclear.

Anthocyanin concentrations in wine determine wine colour-one of the important characteristics that contribute to overall red wine quality. Somers and Evans (1974) demonstrated significant positive correlation between wine quality ratings given by independent judges and colour density of Cabernet Sauvignon and Shiraz wines.

Under the current climate regime, the modelled Cabernet Sauvignon and Shiraz anthocyanin concentrations (in $\mathrm{mg}$ malvidin-3- $O$-glucoside equivalents per gram berry fresh weight) in the WA GIs ranged from about $1.4 \mathrm{mg} / \mathrm{g}$ in the warmer Swan Districts region to $1.9 \mathrm{mg} / \mathrm{g}$ in the Great Southern region (Figs. 6a, 7a). Shiraz and Cabernet Sauvignon typically produce medium- to intense-coloured wines, and anthocyanin concentrations above $1.7 \mathrm{mg} / \mathrm{g}$ are required to produce intensely red-coloured wine (Iland et al. 2004). Considering this benchmark value, the progressive reductions in the modelled Cabernet Sauvignon and Shiraz anthocyanin concentrations under the projected climate change suggest a reduction in wine quality in most of the wine regions of WA. By 2050, under the most warming climate scenario (csiro_mk3_5) and without adaptive management, all WA wine regions are projected to produce Cabernet Sauvignon grapes with anthocyanin concentrations of less than $1.7 \mathrm{mg} / \mathrm{g}$, suggesting an overall wine quality reduction in the WA GIs.

The patterns of changes in Cabernet Sauvignon and Shiraz anthocyanin concentrations under the high and low warming scenario are similar: all show a southward shifting of the current spatial distributions. This is suggestive of justification for relocation of vineyards to the south to maintain current grape berry quality under climate change and has been proposed by other researchers (Tate 2001; Webb et al. 2008). However, spatial distributions of projected anthocyanin concentrations suggest that the success of vineyard shifting is likely to be limited and dependent on the magnitude of the future warming. For example, under the least warming climate scenario (miroc3_2 medres), areas that currently have the potential to produce Cabernet Sauvignon grapes with anthocyanins levels more than 1.7 are unlikely to be available for the northern half and north-eastern parts of Margaret River, northern areas of Manjimup and the Great Southern region by 2030. Collectively, these areas represent the larger proportion of the WA wine industry. Cabernet Sauvignon anthocyanin concentrations of above $1.7 \mathrm{mg} / \mathrm{g}$ is projected only in the southern parts of the Great Southern region by 2070 (Fig. 6). 
Reductions in anthocyanin concentrations are projected to be even more intense under the most warming climate scenario. By 2070, Cabernet Sauvignon and Shiraz grapes from the southern part of Geographe to the Great Southern are projected to have similar levels of anthocyanin concentrations as those currently found in areas from the Swan District to northern Geographe (Figs. 6, 7). The detailed spatial information provided here allows assessment of the degree of effectiveness (in terms of berry colour retention to the heuristic value $1.7 \mathrm{mg} / \mathrm{g}$ ) of relocation as an adaptation strategy. Accordingly, it is suggested that adaptation by shifting southwards alone may offer limited scope since even the southern WA regions will likely become too warm to promote anthocyanin accumulation. However, adaptation may be achieved by deploying several other additional or multilayered strategies such as those enumerated and discussed in Nicholas and Durham (2012).

Trends in grape berry TA and its implication for wine quality

Similar to the observations for anthocyanins, under baseline climate conditions, berry TA levels show considerable regional differences, which are broadly reflective of regional climate patterns. Varietal differences in TA levels of the order Chardonnay $\gg$ Shiraz $>$ Cabernet Sauvignon were also apparent under the baseline climate conditions. Modelled results for the projected climate conditions suggest that the magnitude of impacts on TA levels will vary across regions, varieties and the magnitude of warming (GCM) considered. For the majority of cases, the models project reductions in TA levels while in some cases, such as Cabernet Sauvignon in the Margaret River region, little or no reduction is apparent (Table 3). The Cabernet Sauvignon TA model used here is a function of the growing season diurnal temperature range and the minimum temperature of the berry-ripening period. Under the projected climate, there is a dampening of the growing season diurnal temperature fluctuation in part due to the elevation of the ripening period minimum temperatures. The apparent stability of Cabernet Sauvignon TA in the Margaret River region was thus a consequence of the narrowing diurnal range offsetting the unfavourable effects of rising minimum temperature during the ripening period. The largest projected reductions in median TA, compared to current levels, range from $12 \%$ for Cabernet Sauvignon in the Swan Districts region, $15 \%$ for Shiraz in the Peel and Great Southern regions, to $42 \%$ for Chardonnay in the Swan Districts region by 2070 under the csiro_mk3 5 climate scenario (Table 3, Figs. 8, 9, 10). Chardonnay is also the most sensitive of the three varieties across all the WA regions, suggesting that the impact of the projected warming on loss of acids is likely to be greater on cool- than on warm-climate adapted varieties.

It is long accepted that balanced acid properties help wine to maintain freshness, in addition to determining the taste of wines
(Mato et al. 2005; Conde et al. 2007; Sweetman et al. 2009). However, there is no a commonly accepted TA range for producing quality wines. Winkler (1974) suggested a TA range (in $\mathrm{g} / \mathrm{L}$ ) between 3 and 9 to be optimum for wine making whereas Conde et al. (2007) specified a narrower range of 6.5-8.5. Jackson and Lombard (1993) consider that wine TA levels above 10 or below 6-7 are too tart or bland, respectively. On the basis of the above guidelines, according to the modelling results of this study, the majority of the WA wine regions have TA levels close to the optimum for making naturally balanced wines. However, under the most warming scenario by 2070 , the median TA levels across the northern wine regions are projected to be lower than the thresholds suggested by Conde et al. (2007) and Jackson and Lombard (1993). Reductions in berry acids for these regions are likely to impact on wine quality, requiring wineries to use supplementary acids to balance the low levels of native organic acids in musts and to increase wine stability. Acid additions represent extra cost for wineries (e.g. Walker and Blackmore 2012) and the resulting wine is considered less satisfactory compared to naturally balanced acids (Gladstones 1992). Nonetheless, such a practice at the winemaking level can be part of a suite of options to managing potential impact of climate.

\section{Conclusion}

This study has provided a first-of-its-type assessment of potential impacts of the projected changes in the climate system on two traits of grape berry composition-anthocyanin and TA levels-across all the WA wine GIs. Assessments of the type performed here involve several layers of inputs, each with its own unquantified uncertainty. Notwithstanding this limitation, the results provide useful insights on the likely magnitudes and trends of climate impact (both spatially and temporally) that are consistent with our current understanding how these berry traits respond to climate.

The results indicate that for the varieties examined here, without effective management intervention, the levels of anthocyanin and TA are likely to decline to an extent that the grapes become less than optimal for making naturally balanced premium table wines. While the climate impacts on berry composition generally intensify with the increase in projection period, the magnitudes of impacts vary with region, variety and the degree of warming (GCM). Overall, while the advancement of harvest date is greatest in the cooler southern regions, the quality levels in the future indicate that the currently already warm northern regions, particularly the Swan Districts and Perth Hills, will be under greater pressure than the southern cooler regions. Without effective adaptation, it can be expected that reductions in berry quality in the currently established WA wine GIs could affect the "regional characteristics" of wines. 
Acknowledgements The work reported here was supported by a scholarship from the CSIRO Climate Adaptation Flagship program and a postgraduate research grant from the Grape and Wine Research and Development Corporation to N.N.B.

Open Access This article is distributed under the terms of the Creative Commons Attribution License which permits any use, distribution, and reproduction in any medium, provided the original author(s) and the source are credited.

\section{References}

Ashenfelter O (2008) Predicting the quality and prices of Bordeaux wine. Econ J 118:174-184

Barnuud NN (2012) Determining climate change impacts on viticulture in Western Australia. PhD Thesis. Curtin University, 206 pp. http:// espace.library.curtin.edu.au:80/R?func=dbin-jump-full\&local base $=$ gen01-era02\&object_id $=186490$

Barnuud NN,Zerihun A, Gibberd M,Bates B (2013) Berry composition and climate: responses and empirical models. Int J Biometeorol. doi: 10.1007/s00484-013-0715-2

Bindi M, Fibbi L, Gozzini B, Orlandini S, Miglietta F (1996) Modelling the impact of future climate scenarios on yield and yield variability of grapevine. Clim Res 7:213-224

Bradley NL, Leopold AC, Ross J, Huffaker W (1999) Phenological changes reflect climate change in Wisconsin. Proc Natl Acad Sci USA 96:9701-9704

Caffarra A, Eccel E (2011) Projecting the impacts of climate change on the phenology of grapevine in a mountain area. Aust J Grape Wine Res 17:52-61

Chakraborty S, Murray G, Magarey P, Yonow T, O’Brien R, Croft B, Barbetti M, Sivasithamparam K, Old K, Dudzinski M (1998) Potential impact of climate change on plant diseases of economic significance to Australia. Australas Plant Pathol 27:15-35

Conde C, Silva P, Fontes N, Dias ACP, Tavares RM, Sousa MJ, Agasse A, Delrot S, Gerós H (2007) Biochemical changes throughout grape berry development and fruit and wine quality. Structure 1:1-22

CSIRO and Bureau of Meteorology (2007) Climate change in Australia-Technical report. CSIRO, Melbourne

Esteban MA, Villanueva MJ, Lissarrague JR (2002) Relalationships between different berry components in Tempranillo (Vitis vinifera L.) grapes from irrigated and non-irrigated vines during ripening. $J$ Sci Food Agric 82:1136-1146

Francis I, Newton J (2005) Determining wine aroma from compositional data. Aust J Grape Wine Res 11:114-126

Gladstones J (1992) Viticulture and environment. Winetitles, Adelaide

Hall A, Jones G (2009) Effect of potential atmospheric warming on temperature based indices describing Australian winegrape growing conditions. Aust J Grape Wine Res 15:97-119

Hannah L, Roehrdanz PR, Ikegami M, Shepard AV, Shaw MR, Tabor G, Zhi L, Marquet A, Hijmans RJ (2013) Climate change, wine, and conservation. Proc Natl Acad Sci USA 110:6907-6912

Hayhoe K, Cayan D, Field CB, Frumhoff PC, Maurer EP, Miller NL, Moser SC, Schneider SH, Cahill KN, Cleland EE, Dale L, Drapek R, Hanemann RM, Kalkstein LS, Lenihan J, Lunch CK, Neilson RP, Sheridan SC, Verville JH (2004) Emissions pathways, climate change, and impacts on California. Proc Natl Acad Sci USA 101: $12422-12427$

Hennessy KJ, Whetton PH, McGregor JL, Katzfey JJ, Page CM, Nguyen K (1998) Fine resolution climate change scenarios for New South Wales-Annual Report 1997-98. CSIRO Atmospheric Research consultancy report for NSW EPA
Iland P, Bruer N, Edwards G, Weeks S, Wilkes E (2004) Chemical analysis of grapes and wine: techniques and concepts. Iland Wine Promotions, Adelaide

IPCC (2007) In: Solomon S, Qin D, Manning M, Chen Z, Marquis M, Averyt KB, Tignor M, Miller HL (eds) Climate Change 2007: The Physical Science Basis. Contribution of Working Group I to the Fourth Assessment Report of the Intergovernmental Panel on Climate Change. Cambridge University Press, Cambridge

Jackson D, Lombard P (1993) Environmental and management practices affecting grape composition and wine quality-A review. Am J Enol Vitic 44:409-430

Jones GV (2006) Climate and terrior: impacts of cliamte variability and change on wine. In: Macqueen RW, Meinert LD (eds) Fine wine and terroir - the geoscience perspective. Geoscience Canada Reprint Series No. 9; Geological Association of Canada

Jones GV, Davis RE (2000a) Using a synoptic climatological approach to understand climate-viticulture relationships. Int J Climatol 20:813-837

Jones GV, Davis RE (2000b) Climate influences on grapevine phenology, grape composition, and wine production and quality for Bordeaux, France. Am J Enol Vitic 51:249-261

Jones GV, White MA, Cooper OR, Storchmann K (2005) Climate change and global wine quality. Clim Chang 73:319-343

Jones DA, Wang W, Fawcett R (2007) Climate data for the Australian Water Availability Project: final Milestone Report. National Climate Centre, Bureau of Meteorology, Melbourne

Kliewer W, Torres R (1972) Effect of controlled day and night temperatures on grape coloration. Am J Enol Vitic 23:71-77

Lobell DB, Field CB, Cahill KN, Bonfils C (2006) Impacts of future climate change on California perennial crop yields: model projections with climate and crop uncertainties. Agric For Meteorol 141: 208-218

Mato I, Suarez-Luque S, Huidobro JF (2005) A review of the analytical methods to determine organic acids in grape juices and wines. Food Res Int 38:1175-1188

Mitchell TD (2003) Pattern scaling: an examination of the accuracy of the technique for describing future climates. Clim Chang 60:217-242

Mori K, Goto-Yamamoto N, Kitayama M, Hashizume K (2007) Loss of anthocyanins in red-wine grape under high temperature. J Exp Bot 58:1935-1945

Mpelasoka FS, Chiew FHS (2009) Influence of rainfall scenario construction methods on runoff projections. J Hydrometeorol 10:11681183

Nemani R, White M, Cayan D, Jones G, Running S, Coughlan J, Peterson D (2001) Asymmetric warming over coastal California and its impact on the premium wine industry. Clim Res 19:25-34

Nicholas KA, Durham WH (2012) Farm-sclae adaptation and vulnerability to environmental stresses: Insights from winegroing in Nothern California. Glob Environ Chang 22:483-494

Perkins S, Pitman A, Holbrook N, McAneney J (2007) Evaluation of the AR4 climate models' simulated daily maximum temperature, minimum temperature, and precipitation over Australia using probability density functions. J Clim 20:4356-4376

Sadras VO, Petrie PR (2011) Climate shifts in south-eastern Australia: early maturity of Chardonnay, Shiraz and Cabernet Sauvignon is associated with early onset rather than faster ripening. Aust J Grape Wine Res 17:199-205

Sadras V, Soar C, Petrie P (2007) Quantification of time trends in vintage scores and their variability for major wine regions of Australia. Aust J Grape Wine Res 13:117-123

Salinari F, Giosue S, Rossi V, Tubiello F, Rosenzweig C, Gullino M (2007) Downy mildew outbreaks on grapevine under climate change: elaboration and application of an empirical statistical model. EPPO Bull 37:317-326

Somers TC, Evans ME (1974) Wine quality: correlations with colour density and anthocyanin equilibria in a group of young red wines. J Sci Food Agric 25:1369-1379 
Storchmann K (2005) English weather and Rhine wine quality: an ordered probit model. J Wine Res 16:105-120

Sweetman C, Deluc L, Cramer G, Ford C, Soole K (2009) Regulation of malate metabolism in grape berry and other developing fruits. Phytochemistry 70:1329-1344

Tate A (2001) Global warming's impact on wine. J Wine Res 12:95-109

Walker RR, Blackmore DH (2012) Potassium concentration and pH interrelationships in grape juice and wine of Chardonnay and Shiraz from a range of rootstocks in different environments. Aust J Grape Wine Res 18:183-192

Webb L, Whetton P, Barlow E (2007) Modelled impact of future climate change on the phenology of winegrapes in Australia. Aust J Grape Wine Res 13:165-175

Webb L, Whetton P, Barlow E (2008) Climate change and winegrape quality in Australia. Clim Res 36:99-111
Webb LB, Whetton PH, Barlow EWR (2011) Observed trends in winegrape maturity in Australia. Glob Chang Biol 17:27072719

Whetton P, McInnes K, Jones R, Hennessy K, Suppiah R, Page C, Bathols J, Durack P (2005) Australian climate change projections for impact assessment and policy application: a review. CSIRO Marine and Atmospheric Reserch Papers 001

White M, Diffenbaugh N, Jones G, Pal J, Giorgi F (2006) Extreme heat reduces and shifts United States premium wine production in the 21st century. Proc Natl Acad Sci USA 103:11217-11222

Winkler A (1974) General Viticulture University of California Press, Berkeley, Los Angeles, London

Zhang XC (2005) Spatial downscaling of global climate model output for site-specific assessment of crop production and soil erosion. Agric For Meteorol 135:215-229 